\title{
Gene Expression Profiling as an Adjunctive Measure to Guide the Management of Indeterminate, High-Risk Choroidal Melanocytic Lesions: A Pilot Study
}

\author{
Ezekiel Weis ${ }^{a, b}$ Kelsey Roelofs ${ }^{a}$ Matthew Larocque ${ }^{c}$ Albert Murtha $^{d}$ \\ ${ }^{a}$ Department of Ophthalmology and Visual Sciences, University of Alberta, Edmonton, AB, Canada; \\ ${ }^{b}$ Department of Surgery, University of Calgary, Calgary, AB, Canada; ' ${ }^{c}$ Division of Medical Physics, \\ Department of Oncology, University of Alberta, Edmonton, AB, Canada; ${ }^{\mathrm{d}}$ Department of Oncology, \\ University of Alberta, Edmonton, AB, Canada
}

\section{Keywords}

Gene expression profiling - Uveal melanoma · Plaque brachytherapy · Fine needle aspiration biopsy · Choroidal nevus

\begin{abstract}
Purpose: To describe our early experience with gene expression profiling (GEP) assessment for juxtafoveal, subfoveal, and peripapillary indeterminate high-risk melanocytic lesions to assist in making early treatment decisions in patients who did not feel comfortable with either close observation or definitive treatment. Methods: A prospective cohort of patients with indeterminate lesions who underwent GEP were enrolled. Nonparametric statistical analysis was utilized given the small sample size. Results: Fifteen patients were included in this series. Six (40\%) were class $1 \mathrm{~A}$ and 9 $(60 \%)$ class $1 \mathrm{~B}$. Class $1 \mathrm{~A}$ and $1 \mathrm{~B}$ lesions had a median of three and four clinical risk factors, respectively $(p=0.27)$. There was no statistically significant difference for the largest basal diameter between the classes $(p=0.31)$; however, class 1B lesions were thicker than class $1 \mathrm{~A}$ lesions $(p=0.03)$. None of
\end{abstract}

(c) 2018 S. Karger AG, Basel

E-Mail karger@karger.com

www.karger.com/oop the class $1 \mathrm{~A}$ lesions showed definite growth or metastasis over a mean follow-up period of $17.1 \pm 1.8$ months from fine needle aspiration biopsy. All class 1B patients opted for plaque brachytherapy, and to date none of these patients have developed metastasis, with a mean follow-up of $18.7 \pm$ 8.4 months. Conclusion: There may be a role for GEP assessment in high-risk, indeterminate, posteriorly located choroidal lesions to assist in treatment planning.

(c) 2018 S. Karger AG, Basel

\section{Introduction}

Advances over the past few decades have given us powerful tools for controlling uveal melanoma locally and preventing enucleation; however, we have yet to develop an effective treatment to reduce the risk of metastatic disease or to effectively treat it when it occurs [1-3]. Waiting for growth to occur in small lesions identified as high risk by an ophthalmologist can increase the risk of metastasis even when controlling for tumor size (relative risk of 8.1 on univariate analysis and of 3.2 on multivariate analysis 
controlling for tumor size) $[4,5]$. Therefore, high-risk melanocytic lesions $\leq 3 \mathrm{~mm}$ in thickness without any documentation of growth may be offered treatment $[3,5,6]$.

Many clinical characteristics of choroidal melanocytic lesions have been studied and reported as risk factors for growth [7-9] and metastasis $[5,10]$. In addition to clinical and histopathological criteria, chromosomal prognostic factors [11-14] and gene expression profiling (GEP) classification [15-24] have been validated as predictors of metastasis and melanoma-specific mortality. A recent multicenter prospective study of GEP [16] also compared the prognostic performance of GEP compared to TNM classification and chromosome 3 status (as detected by a validated assay which interrogates single nucleotide polymorphisms). That study concluded that that GEP was the most accurate prognostic marker of all factors analyzed. Since then, several additional studies [15-24] have supported this finding.

The challenge in managing "indeterminate" small choroidal melanocytic lesions is determining which represent small melanomas and are therefore likely to grow and/or metastasize versus those that are actually atypical nevi or melanocytic proliferations that have no malignant potential despite traditional risk factors. If we could accurately and reliably predict the natural course of these lesions, early treatment of melanomas before they grow and become more likely to metastasize would save lives, and treatment-associated morbidity/visual loss would be avoided for patients with lesions that are less likely to grow or metastasize.

Therefore, our group has offered GEP assessment for juxtafoveal, subfoveal, and peripapillary high-risk melanocytic lesions that in our center would be offered treatment if they were peripherally located. Our early experience with this algorithm is presented.

\section{Methods}

All data were collected in a prospective and standardized fashion. The patients included in this study had posteriorly located choroidal pigmented melanocytic lesions and fit one of three groups: (1) a lesion that had three or more risk factors for growth with no prior follow-up and the patient felt uncomfortable proceeding with either close observation or treatment, (2) a lesion that was most likely a small melanoma that would be offered treatment in our center, but the patient felt uncomfortable proceeding with treatment for a variety of reasons (e.g., amblyopia in the other eye, fear of "radiation" or its complications, previous health care providers labeling the lesion as a benign "freckle"), or (3) a lesion that had demonstrated growth (either definite or equivocal) based on fundus photographs and/or ultrasound and the patient wanted additional information before choosing either to continue with close observation versus opting for early treatment. Amelanotic lesions were excluded. There were no additional exclusion criteria. The data regarding the 15 patients included in this study were extracted from our prospectively collected database. There were three main outcomes evaluated in this study. First, we wanted to evaluate our biopsy yield for GEP of these small lesions. Second, we wanted to assess whether biopsy results would be used by patients to aid in treatment (or observation) decision making. Third, we wanted to follow the outcomes based on GEP including vision complications from biopsy, growth in those who elected observation, and metastatic and survival data.

Informed consent was obtained from all patients prior to participation in the study. Following discussion regarding the current literature surrounding GEP, including the clinical scenarios in which it has previously been studied (i.e., for prognostication of "confirmed" tumors rather than to provide additional information to help guide treatment of indeterminate lesions), patients were offered either close observation (clinical assessment including direct ophthalmoscopy and B-scan ultrasonography every 3 months) or GEP through fine needle aspiration biopsy (FNAB). When available, prior fundus photographs were reviewed to determine whether or not the lesion had grown.

As all tumors were located post-equatorially, FNAB was performed via a trans-pars plana, transvitreal approach using a 27 -gauge long needle attached to IV extension tubing on a $10-\mathrm{mL}$ syringe. Under visualization with an indirect ophthalmoscope and a $20 \mathrm{D}$ lens, the needle was embedded in the thickest area of the tumor in most cases. If there appeared to be a more "active" area of the lesion (i.e., orange pigment), the biopsy was taken from this area. Suction was applied once the lesion was entered. And this had been achieved, the needle was quickly removed from the eye. The standard method consisted of first pushing air through the needle, followed by drawing up of buffer, and then re-expressing the extraction buffer into the provided specimen container. Definite growth was defined as an increase in basal dimensions by $\geq 250 \mu \mathrm{m}$ over a 5-year period as measured on standard fundus photographs. This cutoff is in keeping with the median rate of nevus enlargement of $0.06 \mathrm{~mm}$ /year reported in a long-term follow-up study by Mashayekhi et al. [25]. Patients had demonstrated "equivocal growth" defined as a slight increase in size but not significant enough to be classified as definite growth.

It is critical to note that this protocol was only offered to patients who presented with classic features consistent with those of a melanocytic lesion. Lesions were defined as being posteriorly located if the posterior edge of the tumor was within $2 \mathrm{~mm}$ of either the optic nerve or the fovea. We ascribed the term "indeterminate" to indicate the relative diagnostic uncertainty for this group of patients who fall between the diagnoses of high-risk choroidal nevus and small choroidal melanoma. Lesion height was determined on $\mathrm{B}$ scan by measuring from the tumor apex to the posterior sclera. High risk was defined as three or more risk factors for growth (tumor thickness $>2.0 \mathrm{~mm}$, posterior margin $\leq 3 \mathrm{~mm}$ to the optic nerve, subretinal fluid, visual symptoms, orange pigment, hollow on ultrasound, absent drusen or absent halo) [7-9]. Subretinal fluid was recorded as a risk factor if it was noted either clinically or on optical coherence tomography.

Visual acuity was obtained using a Snellen chart; acuities were converted to logarithm of the minimum angle of resolution (logMAR). Basic demographics including age, gender, laterality, tumor dimensions, and proximity to the fovea and optic nerve head 
Table 1. Baseline characteristics and GEP results

\begin{tabular}{|c|c|c|c|c|c|c|c|c|c|c|c|c|}
\hline $\begin{array}{l}\text { Patient } \\
\text { No. }\end{array}$ & $\begin{array}{l}\text { Age, } \\
\text { years }\end{array}$ & $\begin{array}{l}\text { GEP } \\
\text { result }\end{array}$ & $\begin{array}{l}\text { Proba- } \\
\text { bility }\end{array}$ & $\begin{array}{l}\mathrm{LBD} \\
\mathrm{mm}\end{array}$ & $\begin{array}{l}\text { Height, } \\
\mathrm{mm}\end{array}$ & $\begin{array}{l}\text { AJCC 8th } \\
\text { edition } \\
\text { T category } \\
\text { (stage) }\end{array}$ & $\begin{array}{l}\text { Distance } \\
\text { to optic } \\
\text { disc, } m m\end{array}$ & $\begin{array}{l}\text { Distance } \\
\text { to fovea, } \\
\mathrm{mm}\end{array}$ & $\begin{array}{l}\text { Change over } \\
\text { time }\end{array}$ & $\begin{array}{l}\text { Time } \\
\text { followed } \\
\text { prior to } \\
\text { GEP, years }\end{array}$ & Treatment & $\begin{array}{l}\text { Follow-up } \\
\text { from GEP, } \\
\text { months }\end{array}$ \\
\hline 1 & 83 & $1 \mathrm{~B}$ & 1.12 & 9 & 2.70 & T1a (I) & 1 & 1 & equivocal change & 2 & plaque & 40 \\
\hline 2 & 47 & $1 \mathrm{~B}$ & 0.85 & 2 & 2.08 & T1a (I) & 3 & 0.25 & definitive growth & 10 & plaque & 19 \\
\hline 4 & 36 & $1 \mathrm{~B}$ & 0.97 & 3 & 2.09 & T1a (I) & 1 & 1 & no growth & 2 & plaque & 22 \\
\hline 5 & 65 & $1 \mathrm{~B}$ & 1.04 & 8 & 2.08 & T1a (I) & 2.5 & 0 & no growth & 2 & plaque & 20 \\
\hline 6 & 50 & $1 \mathrm{~A}$ & 1.04 & 7 & 2.42 & T1a (I) & 4.5 & 2 & no growth & 0.7 & TTT & 20 \\
\hline 10 & 40 & $1 \mathrm{~A}$ & 1.15 & 3 & flat & T1a (I) & 0 & 1 & no growth & 0.3 & observation & 17 \\
\hline 11 & 46 & $1 \mathrm{~A}$ & 0.77 & 9 & flat & T1a (I) & 2 & 2 & no growth & 8 & observation & 17 \\
\hline 12 & 56 & $1 \mathrm{~B}$ & 1.02 & 8 & 2.00 & T1a (I) & 1 & 0.5 & equivocal change & 4 & plaque & 17 \\
\hline $\begin{array}{l}13 \\
\text { (choroid) }\end{array}$ & 56 & $1 \mathrm{~B}$ & 0.65 & 9 & 3.00 & T1a (I) & 3 & 0 & $\begin{array}{l}\text { not followed prior to } \\
\text { GEP }\end{array}$ & N/A & plaque & 12 \\
\hline 14 & 47 & $1 \mathrm{~B}$ & 0.39 & 4 & 1.80 & T1a (I) & 5 & 2.5 & $\begin{array}{l}\text { not followed prior to } \\
\text { GEP }\end{array}$ & N/A & plaque & 12 \\
\hline 15 & 61 & $1 \mathrm{~B}$ & 0.66 & 6 & 2.38 & T1a (I) & 5 & 2.0 & no growth & 10 & plaque & 12 \\
\hline
\end{tabular}

GEP, gene expression profiling; LBD, largest basal diameter; N/A, not available; TTT, transpupillary thermotherapy. ${ }^{1}$ Outside fundus photographs were used to determine whether a lesion had changed over time, provided they were of sufficient quality to make a reliable judgement.

were recorded. Due to the small sample size, nonparametric tests were utilized to compare values between groups. The Mann-Whitney $\mathrm{U}$ (Wilcoxon rank-sum) test was used to compare characteristics between class $1 \mathrm{~A}$ and $1 \mathrm{~B}$ tumors when the groups were independent and the Wilcoxon signed-rank test when the groups were not independent.

\section{Results}

Of the 15 patients included in this series, $11(73 \%)$ were male. Fourteen of the 15 patients were AJCC 8th edition [26] stage I (T1a) and 1 patient was stage IIA (T2a). Two patients (13\%) presented with visual symptoms (blurred/decreased vision and/or photopsia). The remaining 12 patients were picked up on routine examination and subsequently referred to the ocular oncology service given the suspicious nature or possible early growth of their lesion. The mean $( \pm \mathrm{SD})$ age at the time of GEP testing was $53 \pm 11$ years (range $39-83$ years). Eleven patients were either followed prior to their GEP biopsy by our service or had reliable fundus photographs sent from their referring physician. The mean pre-GEP follow-up for these 11 patients was $4 \pm 4$ years (Table 1 ).

The mean distance from the fovea was $1.3 \pm 1.1 \mathrm{~mm}$ (range $0-4 \mathrm{~mm}$ ), with a mean distance from the optic nerve head of $2.1 \pm 1.7 \mathrm{~mm}$ (range $0-3 \mathrm{~mm}$ ). The mean largest basal diameter (LBD) was $6.2 \pm 3.2 \mathrm{~mm}$ (range $2-13 \mathrm{~mm}$ ). The mean tumor height, as measured by contact A or B scans, was $2.1 \pm 0.5 \mathrm{~mm}$, ranging from 0.85 to $3.0 \mathrm{~mm}$ (Table 1 ). The individual tumor risk factors for growth/metastasis can be seen in Table 2, and corresponding color fundus photographs and contact $\mathrm{B}$ scans of all patients included in this study can be seen in Figure 1 (class $1 \mathrm{~A}$ lesions) and Figure 2 (class 1B lesions). 
Table 2. Clinical risk factors for growth of all lesions

\begin{tabular}{|c|c|c|c|c|c|c|c|c|c|c|c|}
\hline $\begin{array}{l}\text { Patient } \\
\text { No. }\end{array}$ & $\begin{array}{l}\text { GEP } \\
\text { result }\end{array}$ & $\begin{array}{l}\text { Height } \\
>2 \mathrm{~mm}\end{array}$ & $\begin{array}{l}\text { Presence of } \\
\text { subretinal } \\
\text { fluid }^{1}\end{array}$ & $\begin{array}{l}\text { Presence of } \\
\text { orange } \\
\text { pigment }\end{array}$ & $\begin{array}{l}\text { Absence } \\
\text { of drusen }\end{array}$ & $\begin{array}{l}\text { Visual } \\
\text { symptoms }\end{array}$ & $\begin{array}{l}\text { Proximity to } \\
\text { optic disc } \\
\text { margin }<3 \mathrm{~mm}\end{array}$ & $\begin{array}{l}\text { Acoustically } \\
\text { hollow on } \\
\text { ultrasound }\end{array}$ & $\begin{array}{l}\text { Presence } \\
\text { of halo }\end{array}$ & $\begin{array}{l}\text { Number of } \\
\text { risk factors } \\
\text { of all } 8\end{array}$ & $\begin{array}{l}\text { Number of } \\
\text { risk factors of } \\
5 \text { (TFSOM) }\end{array}$ \\
\hline 2 & $1 \mathrm{~B}$ & + & + & + & + & - & + & - & - & 5 & 4 \\
\hline 3 & $1 \mathrm{~A}$ & + & - & + & - & - & + & - & - & 3 & 3 \\
\hline 5 & $1 \mathrm{~B}$ & + & - & + & - & - & + & + & - & 4 & 3 \\
\hline 6 & $1 \mathrm{~A}$ & + & - & + & + & - & - & + & - & 4 & 2 \\
\hline 7 & $1 \mathrm{~A}$ & - & + & + & - & - & + & - & - & 3 & 3 \\
\hline 8 & $1 \mathrm{~A}$ & - & + & + & + & - & + & + & - & 5 & 3 \\
\hline 11 & $1 \mathrm{~A}$ & - & - & - & + & - & + & - & - & 2 & 1 \\
\hline 12 & $1 \mathrm{~B}$ & + & - & - & + & - & + & - & - & 3 & 2 \\
\hline 13 & $1 \mathrm{~B}$ & + & - & - & + & + & + & - & - & 4 & 3 \\
\hline 14 & $1 \mathrm{~B}$ & - & + & + & + & - & - & + & + & 5 & 2 \\
\hline 15 & $1 \mathrm{~B}$ & + & + & + & - & - & - & + & + & 5 & 3 \\
\hline
\end{tabular}

GEP, gene expression profiling. ${ }^{1}$ Presence of subretinal fluid was determined by optical coherence tomography over the lesion.

Six of the 15 patients $(40 \%)$ included in our study had a class $1 \mathrm{~A}$ GEP and 9 were GEP class $1 \mathrm{~B}(60 \%)$. The class $1 \mathrm{~B}$ tumors tended to be larger (mean LBD 6.9 vs. $5.1 \mathrm{~mm}$ for class $1 \mathrm{~A}$ ) and had a greater number of clinical risk factors for growth (class $1 \mathrm{~B}$ mean 4.1 vs. class $1 \mathrm{~A}$ mean 3.5 ); however, neither of these differences reached statistical significance in this small study. Interestingly, most class $1 \mathrm{~B}$ versus $1 \mathrm{~A}$ tumors being $\geq 2.0 \mathrm{~mm}$ thick ( 89 vs. $33 \%$, respectively) and the mean tumor height between the groups (class $1 \mathrm{~A}=1.8 \mathrm{~mm}$, class $1 \mathrm{~B}=2.2 \mathrm{~mm}$ ) were statistically significantly different $(p=0.03)$. The number of clinical risk factors between the class $1 \mathrm{~A}$ and $1 \mathrm{~B}$ tumors was not statistically significantly different $(p=0.27$ and $p=0.70$ (Table 3 ). There was no statistically significant relationship between the LBD $(p=0.31)$ and the GEP probability value. A successful GEP classification was possible in all 15 cases and all discriminant scores were $\geq 0.100$, indicating normal confidence.

Prior to FNAB, the mean $\log$ MAR visual acuity of all patients included in the study was $0.09 \pm 0.13(20 / 25)$. One patient suffered a complication from FNAB. In this
Table 3. Comparison of total number of risk factors, tumor thickness as measured by contact $\mathrm{A}$ and $\mathrm{B}$ ultrasound, and LBD between class $1 \mathrm{~A}$ and $1 \mathrm{~B}$ tumors

\begin{tabular}{llll}
\hline & $\begin{array}{l}\text { Class 1A } \\
(n=6)\end{array}$ & $\begin{array}{l}\text { Class 1B } \\
(n=9)\end{array}$ & $\begin{array}{l}p \\
\text { value }^{1}\end{array}$ \\
\hline Risk factors of all 8 $^{2}$ & $3.5(3.0) \pm 0.8$ & $4.1(4.0) \pm 0.9$ & 0.27 \\
Risk factors for 5 $^{3}$ & $2.5(1.8) \pm 1.1$ & $2.9(3.0) \pm 1.1$ & 0.70 \\
Tumor thickness, mm & $1.8 \pm 0.5$ & $2.2 \pm 0.4$ & 0.03 \\
LBD, mm & $5.1 \pm 0.5$ & $6.9 \pm 3.5$ & 0.31 \\
\hline
\end{tabular}

Values are presented as mean (median) \pm SD or mean \pm SD. LBD, largest basal diameter. ${ }^{1}$ A Mann-Whitney U test was performed with $\alpha=0.05 .{ }^{2}$ Risk factors included in this analysis: tumor thickness $>2 \mathrm{~mm}(\mathrm{~T})$, distance to optic disc margin $<3 \mathrm{~mm}(\mathrm{M})$, presence of orange pigment $(\mathrm{O})$, presence of subretinal fluid $(\mathrm{F})$, symptoms (S), absence of drusen, acoustic hollowness on ultrasound, and presence of halo. ${ }^{3}$ Risk factors include TFSOM. 


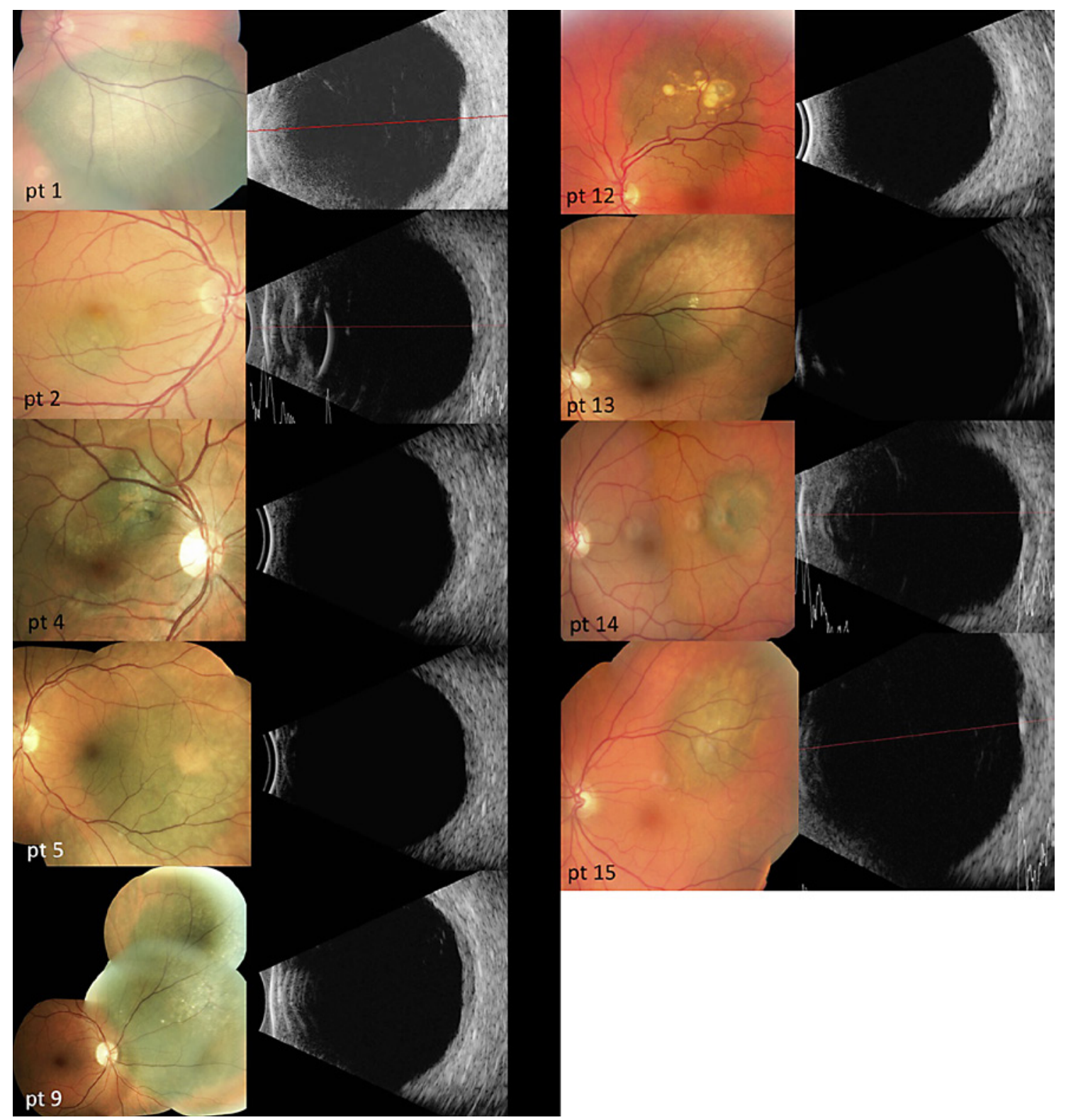

Fig. 1. Color fundus photographs and B-scan ultrasonography of all 6 class 1A lesions.

case, the patient was unaware that he was anticoagulated on clopidogrel. Unfortunately, he developed a significant subretinal hemorrhage resulting in retinal detachment, requiring pars plana vitrectomy and tamponade with intraocular gas. He went on to undergo plaque brachytherapy for his subfoveal GEP class $1 \mathrm{~B}$ lesion (patient No. 1). His final visual acuity was count fingers at 3 feet.

Patient No. 13 had two noncongruous intraocular tumors, one involving the ciliary body and one a choroidal lesion adjacent to the optic nerve. As such, this patient had two unique GEP samples sent. His ciliary body tumor yielded a class 2 GEP, and his choroidal lesion was found to be class $1 \mathrm{~B}$. Only the data regarding this patients' choroidal lesion were included in the analysis. The ciliary body tumor was excluded from all analysis as it did not fit the inclusion criteria of being a posteriorly located choroidal lesion, to which we applied this algorithm. The ciliary body lesion measured $4.3 \mathrm{~mm}$ in thickness and had classic melanocytic clinical, ultrasonographic, and cyto- 


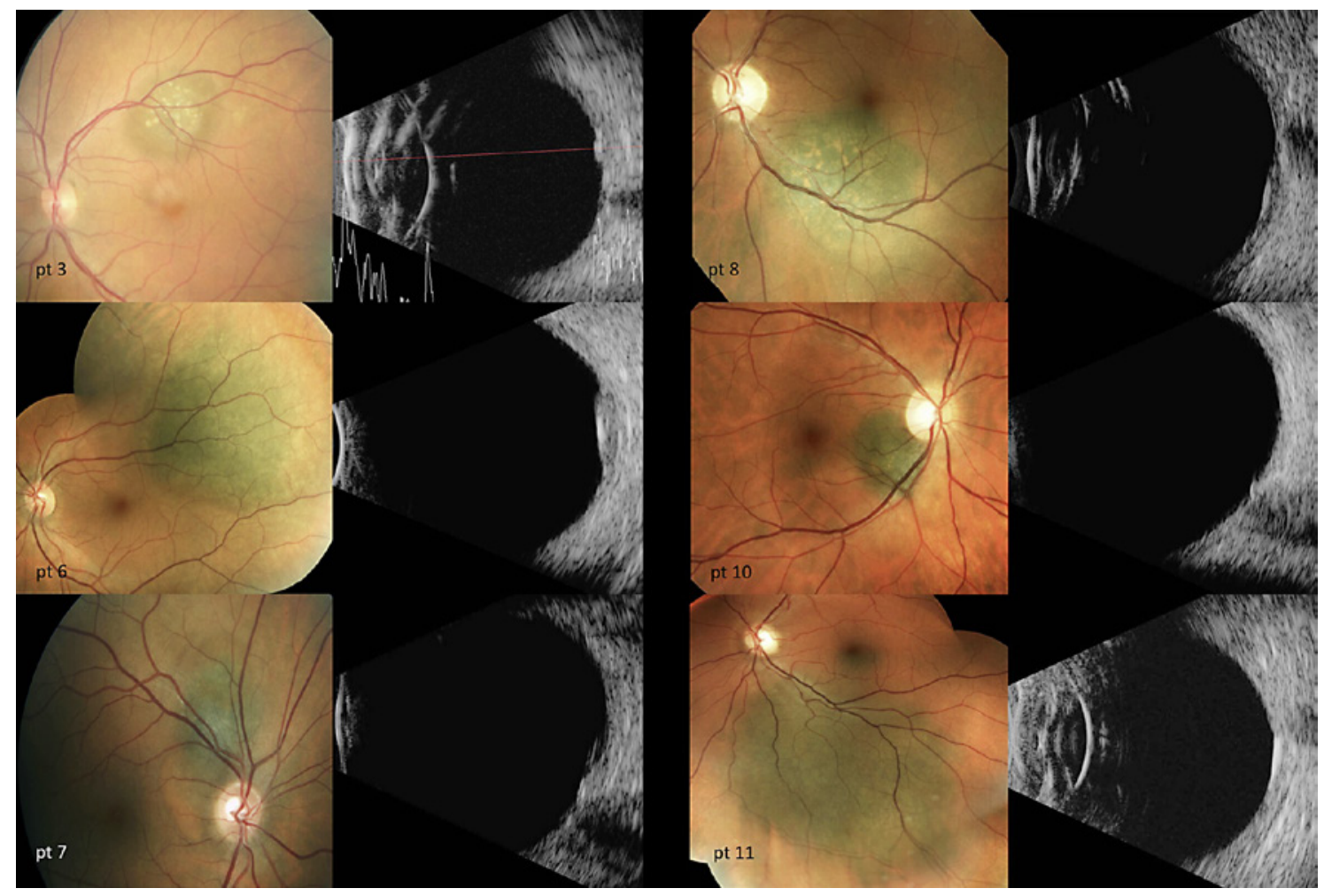

Fig. 2. Color fundus photographs and B-scan ultrasonography of all 9 class $1 \mathrm{~B}$ patients.

logic findings necessitating treatment. We are still awaiting BAP1 testing for this patient.

Overall, the 15 patients included in this study were followed for a mean $( \pm S D)$ of $18.1 \pm 6.7$ months since FNAB, with the class $1 \mathrm{~A}$ patients being followed for slightly less time than the class $1 \mathrm{~B}$ patients $(17.1 \pm 1.8$ vs. $18.7 \pm 8.4$ months, respectively). Five of the 6 patients with GEP class $1 \mathrm{~A}$ tumors were comfortable proceeding with close observation after receiving their GEP result. One requested to be treated with transpupillary thermotherapy (patient No. 6). None of the 5 patients with GEP class 1 A who were observed showed definite growth or metastasis over a mean follow-up period of $17.1 \pm 1.8$ months. Of the 5 class $1 \mathrm{~A}$ patients who were observed following FNAB, there was no statistically significant difference in pre- and post-FNAB logMAR visual acuity with a mean pre-FNAB visual acuity of $20 / 21(\log M A R \quad 0.03 \pm 0.05)$ and a postFNAB visual acuity of $20 / 22(\log M A R \quad 0.05 \pm 0.05)(p=$ 0.32 ).

All of the patients whose choroidal lesions exhibited class 1B GEP elected to be treated with plaque brachytherapy rather than close observation. To date, none of the GEP class $1 \mathrm{~B}$ patients included in this series have de- veloped metastasis or local treatment failure (growth post radiation), and all are alive with a mean follow-up of $18.7 \pm 8.4$ months from GEP to the current date.

\section{Discussion}

As a greater proportion of smaller tumors are being treated, recent research has demonstrated that in addition to a class 2 gene expression profile, LBD is also an independent statistically significant predictor of survival $[18,19]$. This suggests that metastasis is not only a product of a tumor's RNA activity, but also a result of tumor size $[18,19,27]$. Therefore, treating genetically "aggressive" tumors before their size increases may improve survival. In this context, knowledge of a tumor's RNA activity may add useful information for patients to consider when deciding whether to elect early treatment or rather to proceed with close observation until definitive growth of their lesion is documented.

The idea of offering FNAB to patients with indeterminate high-risk lesions is not new. Augsburger et al. [28] proposed utilizing cytology through an FNAB of these 
high-risk indeterminate lesions to provide further information on the malignancy potential of the lesion. However, there are some limitations to using cytology for this purpose, including low yield [28], the subjective component of cytologic assessment of melanocytic lesions [2931 , and the difficulty in distinguishing between lowgrade melanomas and nevi [32]. Augsburger et al. [28] found that in $35 \%$ of cases the aspirate was insufficient for cytologic diagnosis. Of the $65 \%$ of cases which yielded sufficient aspirate for cytodiagnosis, $47.1 \%$ were classified as melanomas; $11.8 \%$ of these were classified as intermediate lesions and $5.9 \%$ were classified as benign nevi on cytopathology. Following FNAB, 12 patients with insufficient aspirates and the 4 patients with intermediate cells were classified as "nevus versus melanoma." With a median follow-up of 2.6 years, the lesions of $8(50 \%)$ of the patients in the "nevus versus melanoma" group subsequently grew, were reclassified as small melanomas, and received treatment.

When discussing the GEP result with the patient in this study, the treating physician again reviewed the risks and benefits associated with plaque brachytherapy versus close observation. In addition, the difference in the "case mix" between the validation studies on GEP and these cases was re-explained and discussed. When empowered with the knowledge that their lesion was found to have a class $1 \mathrm{~B}$ GEP, all patients preferred to proceed with radiation treatment without waiting for definitive documentation of growth. Although the exact risks per case vary, the "average" patient's decision appeared to be based primarily on the knowledge of two key points: (1) they had a $>50 \%$ chance of demonstrating tumor growth if observed (based on having $\geq 3$ clinical risk factors), and (2) their expected 5-year metastasis-free survival if observed until other events which would traditionally prompt treatment with plaque brachytherapy (such as definitive growth) occurred would be approximately $79 \%$ [33]. Of note, several series have documented excellent outcomes with treatment of small melanomas using palladium [34], iodine 125 [35], and ruthenium [36], even for posteriorly located lesions.

The primary weaknesses of our study are the small sample size and the short follow-up time that did not provide sufficient power to properly compare the subgroups or allow for long-term assessment of metastasis. Additionally, one must keep in mind that we did not perform concurrent cytopathology, as is performed in some centers. As such, it is important that this algorithm be used in the correct patient population (those for whom there is no uncertainty regarding the underlying choroidal melanocytic origin of their lesion) as a GEP result will be provided irrespective of the tissue sampled [37]. Furthermore, this treatment algorithm is challenging to explain to a patient, and therefore may not be suitable for all patients. Understanding the limitations of current research in terms of its external generalizability (case mix) for predicting future survival in this subgroup of patients is difficult, but we felt that all of the patients in this series had a good grasp of the information and were well informed. Finally, one must keep in mind that discordant GEP classification within a lesion is possible [38] and that a class $1 \mathrm{~A}$ result does not obviate the need for ongoing close follow-up. In the near future, incorporation of newer genetic tests, such as PRAME testing, may further improve the accuracy and prognostication information derived from our use of GEP in this patient population, as it has been reported that $0 \%$ of class 1 PRAME-negative patients developed metastasis within 5 years [39].

\section{Conclusion}

GEP assessment via FNAB for a highly selective group of patients with high-risk melanocytic lesions of the posterior pole was helpful in providing further information to aid in treatment decision making in a cohort of patients that did not feel comfortable continuing with either close observation or definitive treatment.

\section{Statement of Ethics}

Ethics approval for a prospective database containing standardized information of all ocular oncology patients seen at our center was obtained from the Health Research Ethics Board for Alberta - Cancer Committee. Consent was obtained from all participants to have demographic data, tumor characteristics, and outcomes collected.

\section{Disclosure Statement}

No funding was received for this study. None of the authors have any financial disclosures to make or proprietary interests to declare. 


\section{References}

1 Harbour JW, Chao DL: A molecular revolution in uveal melanoma: implications for patient care and targeted therapy. Ophthalmology 2014;121:1281-1288.

2 Pereira PR, Nakao A, Lim L, et al: Current and emerging treatment options for uveal melanoma. Clin Ophthalmol 2013;7:1669-1682.

3 Weis E, Salopek TG, McKinnon JG, et al: Management of uveal melanoma: a consensus-based provincial clinical practice guideline. Curr Oncol 2016;23:57-64.

4 Shields C, Shields J, Kiratli H, De Potter P, Cater J: Risk factors for growth and metastasis of small choroidal melanocytic lesions. Ophthalmology 1995;102:1351-1361.

5 Shields C, Furuta M, Thangappan A, et al: Metastasis of uveal melanoma millimeter-bymillimeter in 8033 consecutive eyes. Arch Ophthalmol 2009;127:989-998.

6 Simpson ER, Gallie B, Laperrierre N, et al: The American Brachytherapy Society consensus guidelines for plaque brachytherapy of uveal melanoma and retinoblastoma. Brachytherapy 2014;13:1-14.

7 Shields CL, Cater J, Shields J, Singh D, Santos MC, Carvalho C: Combination of clinical factors predictive of growth of small choroidal melanocytic tumors. Arch Ophthalmol 2000; 118:360-364.

8 Factors predictive of growth and treatment of small choroidal melanoma: COMS Report No. 5. The Collaborative Ocular Melanoma Study Group. Arch Ophthalmol 1997;115: 1537-1544.

9 Shields C, Furuta M, Berman E, et al: Choroidal nevus transformation into melanoma: analysis of 2514 consecutive cases. Arch Ophthalmol 2009;127:981-987.

10 Shields CL, Shields JA, Kiratli H, De Potter P, Cater JR: Risk factors for growth and metastasis of small choroidal melanocytic lesions. Trans Am Ophthalmol Soc 1995;93:259-275; discussion 275-279.

11 Dopierala J, Damato BE, Lake SL, Taktak AFG, Coupland SE: Genetic heterogeneity in uveal melanoma assessed by multiplex ligation-dependent probe amplification. Invest Ophthalmol Vis Sci 2010;51:4898-4905.

12 Prescher G, Becher R: Nonrandom chromosomal abnormalities in primary uveal melanoma. J Natl Cancer Inst 1990;82:1765-1769.

13 Prescher G, Bornfeld N, Hirche H, Horsthemke B, Becher R: Prognostic implications of monosomy 3 in uveal melanoma. Lancet 1993;347:1222-1225.

14 Bronkhorst IHG, Maat W, Jordanova ES, et al: Effect of heterogeneous distribution of monosomy 3 on prognosis in uveal melanoma. Arch Pathol Lab Med 2011;135:1042-1047.
15 Correa ZM, Augsburger JJ: Sufficiency of FNAB aspirates of posterior uveal melanoma for cytologic versus GEP classification in 159 patients, and relative prognostic significance of these classifications. Graefes Arch Clin Exp Ophthalmol 2014;252:131-135.

16 Onken MD, Worley LA, Char DH, et al: Collaborative Ocular Oncology Group report number 1: prospective validation of a multigene prognostic assay in uveal melanoma. Ophthalmology 2012;119:1596-1603.

17 Decatur CL, Ong E, Garg N, et al: Driver mutations in uveal melanoma: associations with gene expression profile and patient outcomes. JAMA Ophthalmol 2016;134:728-733.

18 Corrêa ZM, Augsburger JJ: Independent prognostic significance of gene expression profile class and largest basal diameter of posterior uveal melanomas. Am J Ophthalmol 2016;162:20-27.e1

19 Walter SD, Chao DL, Feuer W, Schiffman J, Char DH, Harbour JW: Prognostic implications of tumor diameter in association with gene expression profile for uveal melanoma. JAMA Ophthalmol 2016;134:734-740.

20 Petrausch U, Martus P, Tonnies H, et al: Significance of gene expression analysis in uveal melanoma in comparison to standard risk factors for risk assessment of subsequent metastases. Eye 2008;22:997-1007.

21 Gill HS, Char DH: Uveal melanoma prognostication: from lesion size and cell type to molecular class. Can J Ophthalmol 2012;47:246253.

22 van Gils W, Lodder EM, Mensink HW, et al: Gene expression profiling in uveal melanoma: two regions on $3 p$ related to prognosis. Invest Ophthalmol Vis Sci 2008;49:4254-4262.

23 Onken MD, Worley LA, Ehlers JP, Harbour JW: Advances in brief gene expression profiling in uveal melanoma reveals two molecular classes and predicts metastatic death. Cancer Res 2004;64:7205-7209.

24 Worley LA, Onken MD, Person E, et al: Transcriptomic versus chromosomal prognostic markers and clinical outcome in uveal melanoma. Clin Cancer Res 2007;13:1466-1472.

25 Mashayekhi A, Siu S, Shields CL, Shields JA: Slow enlargement of choroidal nevi: a longterm follow-up study. Ophthalmology 2011; 118:382-388.

26 Amin MB, Edge S, Greene F, Byrd DR, Brookline RK, Washington MK, Gershenwald JE, Compton CC, Hess KR, Sullivan DC, Jessup JM, Brierley JD, Gaspar LE, Schilsky RL, Balch CM, Winchester DP, Asare EA, Madera M, Gress DM, Meyer LR: AJCC Cancer Staging Manual, ed 8. New York, Springer International Publishing, 2017.
27 Kujala E, Damato B, Coupland SE, Desjardins L, Bechrakis NE, Grange JD, Kivelä T: Staging of ciliary body and choroidal melanomas based on anatomic extent. J Clin Oncol 2013; 31:2825-2831.

28 Augsburger JJ, Correa ZM, Schneider S, et al: Diagnostic transvitreal fine-needle aspiration biopsy of small melanocytic choroidal tumors in nevus versus melanoma category. Trans Am Ophthalmol Soc 2002;100:224-225.

29 Callender GR: Malignant melanotic tumors of the eye: a study of histologic types in 111 cases. Trans Am Acad Ophthalmol Otolaryngol 1931;36:131-142.

30 McLean I, Foster W, Zimmerman L, Gamel J: Modifications of Callender's classification of uveal melanoma at the Armed Forces Institute of Pathology. Am J Ophthalmol 1983;96: 502-509.

31 Gamel JW, McLean IW: Quantitative analysis of the Callender classification of uveal melanoma cells. Arch Ophthalmol 1977;95:686691.

32 Eagle RC: The pathology of ocular cancer. Eye (Lond) 2013;27:128-136.

33 Castle biosciences patient report. http://www. myuvealmelanoma.com/wp-content/uploads/2016/10/DDx-UM_Sample_LabReport_V4.4.pdf (accessed April 18, 2018).

34 Semenova E, Finger PT: Palladium-103 radiation therapy for small choroidal melanoma. Ophthalmology 2013;120:2353-2357.

35 Murray TG, Markoe AM, Gold AS, et al: Long-term followup comparing two treatment dosing strategies of (125) I plaque radiotherapy in the management of small/medium posterior uveal melanoma. J Ophthalmol 2013;2013:517032.

36 Salkola S, Heikkonen J, Eskelin S, Kivela T: Management of choroidal melanomas less than $10 \mathrm{~mm}$ in largest basal diameter with a $10 \mathrm{~mm}$ ruthenium plaque. Retina 2014;34: 2110-2120.

37 Klufas MA, Itty S, McCannel CA, Glasgow BJ, Moreno C, McCannel TA: Variable results for uveal melanoma-specific gene expression profile prognostic test in choroidal metastasis. JAMA Ophthalmol 2015;133:1073-1076.

38 Augsburger JJ, Correa ZM, Augsburger BD: Frequency and implications of discordant gene expression profile class in posterior uveal melanomas sampled by fine needle aspiration biopsy. Am J Ophthalmol 2015;159:248256.

39 Field MG, Decatur CL, Kurtenbach S, et al: PRAME as an independent biomarker for metastasis in uveal melanoma. Clin Cancer Res 2016;22:1234-1242.
GEP to Guide the Management of Indeterminate Lesions
Ocul Oncol Pathol 2019;5:102-109

DOI: $10.1159 / 000490252$ 